\title{
ANÁlISE MORFOLÓGICA E QUANTITATIVA DOS OVOS DE SCHISTOSOMA MANSONI EM FEZES HUMANAS *
}

\author{
Sérgio Gomes Coutinho **, Maurício de Andrade ***, Luiz Fernando Ferreira **** \\ e J. Rodrigues da Silva $* * * * *$
}

\begin{abstract}
Os autores, na primeira parte do trabalho, descrevem os principais tipos de ovos de $\mathrm{S}$. mansoni observados em fezes de pacientes originários de zonas endêmicas da esquistossomose e nunca anteriormente submetidos a tratamento. Descrevem a presença de ovos viáveis maduros e imaturos, além de diversos tipos de ovos mortos, inclusive calcificados. Chamam a atenção para a raridade dêste último achado, que entretanto, não deve ser desprezado no contrôle coproscópico após terapêutica antiparasitária. Apresentam fotografias e as dimensóes médias dos ovos observados.

Em uma segunda parte, fazem a contagem dos ovos de $\mathbf{S}$. mansoni por $\mathrm{cm} 3$ de fezes. Encontram maior numero de ovos, tanto viáveis como mortos, nos pacientes portadores da forma hepatoesplênica da doença, do que nos portadores da forma hepatointestinal. Verificaram, entretanto, que as percentagens dos diversos tipos de ovos não se afastam muito. Supóem que, ao lado de outros faútures, um maior número de vermes no hospedeiro deva exercer papel imporiante no desenvolvimento das formas graves da esquistossomose mansoni. Eizconiram também maior numero de ovos, tanto viáveis como mortos, nos individuus menores de 20 anos do que nos maiores de 20 anos de idade. No entanto. a percentagem dos diversos tipos de ovos eliminados náo sofre grandes modificaçoes nos dois grupos de doentes. Acreditam que além de fatôres imunitárics, $c$ envelhecimento dos vermes com o decorrer da parasitose possa ser responsávcl pela diminuição na oviposição.

Os dados relativos à contagem global de ovos de $\mathrm{s}$. mansoni em fezes de pacientes ajastados de zonas endêmicas confirmam, de uma maneira geral, os resultados encontrados por outros autores em áreas endêmicas da esquistossomose mansoni, quando se referem ao maior ou menor número de ovos eliminados, en relação à forma clínica da parasitose e ao grupo etário dos pacientes.
\end{abstract}

\section{INTRODUÇÃO}

Pela observação de que os ovos de $S$. mansoni eliminados em fezes humanas podem apresentar variações em sua morfologia, pareceu-nos de interêsse um estudo mais sistematizado dessas variações. Al- guns dos aspectos a serem presentemente focalizados já foram resumidamente apresentados no $3 .^{\circ}$ Congresso da Sociedade Brasileira de Medicina Tropical (5).

Ottolina (19) estudou profundamente as particularidades anatômicas, citológicas e fisiológicas do miracídio de $S$. mansoni,

\footnotetext{
- Trabalho da Cadeira de Clínica de Doenças Tropicais e Infectuosas da F. M. da Universidade Federal do liio de Janeiro e do Departamento de Ciências Biológicas da Fundação Ensino Especializado de Saúde Pública (FENSP). Realizado $\mathrm{cm}$ parte com auxílio do Grant AI-05188-03 do Institut of Allergy and Infectuous Diseases (Pubiic Heath Service) e do Conselho de Pesquisas da U.F.R.J.

" Professor assistente da F. M. da U.F.R.J. Técnico de Nivel Superior da FENSP, atualmente professor adjunto

** Auxiliar de Ensino da FENSP

*** Chefe do Departamento de Ciências Biológicas da FENSP

**** Professor Catedrático da Cadeira da Clinica de Doenças Tropicais e Infectuosas da F. M. da U.F.R.J.
} 
além do rever pormenorizadamente a literatura sôbre o assunto. A respeito dessas particularidades do miracídio, nada será acrescentado no presente trabalho, o qual tem por finalidade uma apreciação das variações morfológicas globais do ôvo de $S$. mansoni em fezes.

A maioria das publicações referentes à classificação dos tipos de ovos de $S$. mansoni, são baseadas em material obtido por biópsia de reto humano, ou em vísceras de animais de experimentação. No primeiro caso existem os trabalhos de Rodrigues da Silva (28), Arantes Pereira \& col. (22), Viana Martins (15), Pereira (23), Prata (27), além de outros, e no segundo caso os estudos de Pellegrino \& cols. (21), Loos (11). Entretanto, com relação a uma classificação dos ovos de $S$. mansoni em fezes humanas, só temos conhecimento do trabalho de Gliveira (17), que procurou reconhecer nas fezes de um paciente os tipos de ovos descritos por Prata (27), em biópsia retal. Parece-nos entretanto que alguns ovos eliminados pelas fezes podem apresentar aspectos diferentes daqueles observados em biópsia retal, como será descrito mais adiante.

Em uma segunda parte do presente trabalho, os ovos de $S$. mansoni serão analisados também quantitativamente, procurando-se estabelecer correlações entre o número de ovos eliminados por $\mathrm{cm} 3$ de fezes e o grupo etário dos pacientes, se maiores de 20 anos ou menores de 20 anos de idade.

Outra correlação que será efetuada, aquela entre o número de ovos de $S$. mansoni eliminados por cm3 de fezes e a forma clínica da esquistossomose, se hepatoesplênica ou hepatointestinal. Por intermédio desta análise, procura-se demonstrar apenas se o número de ovos de $S$. mansoni eliminados em fezes é maior ou menor neste ou naquele grupo de doentes, sem que se pretenda estabelecer uma relação exata entre o número de ovos e o número de vermes parasitas. No entanto, de uma maneira mais ou menos aproximada, um número maior de ovos nas fezes deverá corresponder a uma carga maior de vermes.

Klöetzel (10) e Barbosa (1), em nosso meio, já haviam relacionado o número de ovos nas fezes com o grupo etário dos pacientes e com as formas clínicas da doença, em áreas endêmicas da esquistossomose.

\section{MATERIAL E METODOS}

Com relação à análise morfológica dos ovos de $S$. mansoni, foram utilizadas fezes de 45 pacientes portadores de esquistossomose mansoni ativa, originários de zonas endêmicas da parasitose, e nunca submetidos anteriormente à terapêutica anti-esquistossomótica.

As fezes emitidas pela manhã eram examinadas após 3 a 4 horas, utilizando-se, para a concentração dos ovos, o método de sedimentação em água, deixando-se o material em repouso durante o tempo de 1 hora.

Após decantação do material sobrenadante, eram examinadas 2 amostras do sedimento entre lâmina e laminula. Assim sendo, foram analisados cêrca de 2000 ovos de $S$. mansoni, e efetuadas várias micro-fotografias dos diversos tipos de ovos observados, estabelecendo-se ainda as suas dimensões.

Com referência à análise quantitativa, foi efetuada a contagem do número de ovos de $S$. monsoni por $\mathrm{cm} 3$ de fezes em $24 \mathrm{pa}-$ cientes dos 45 estudados com relação aos aspectos morfológicos dos ovos. As fezes quando liquefeitas eram desprezadas.

O método de contagem utilizado foi $o$ método de Barbosa (1), modificado por Pe. reira Jr. \& cols. (24): em proveta de 50 $\mathrm{cm} 3$, coloca-se água até $45 \mathrm{~cm} 3$, e em seguida completa-se o volume com fezes até $50 \mathrm{~cm} 3$. A seguir, desagregam-se as fezes com auxilio de um bastão de vidro até ficarem perfeitamente homogeneizadas, e finalmente filtra-se através de gaze dobrada em 8 para outra proveta de $50 \mathrm{~cm} 3$, graduada em $0,5 \mathrm{~cm} 3$. O material é sedimentado durante 1 hora, finda a qual mede-se o volume de sedimento na própria proveta. Decanta-se o material sobrenadante com o auxílio de uma pipeta, a fim de não se alterar o volume do sedimento. Posteriormente pipeta-se $0,1 \mathrm{~cm} 3$ dêste sedimento, e procede-se à contagem dos ovos entre a lâmina e laminula, com o auxílio do microscópio.

Foram examinadas sempre 2 amostras do sedimento, fazendo-se a média entre as duas contagens. O cálculo do número de ovos por cm3 de fezes é baseado no número de ovos evidenciado em $0,1 \mathrm{~cm} 3$ do sedimento, no volume total do sedimento e no volume de fezes utilizado. 


\section{I - ANÁLISE MORFOLÓGICA}

\section{RESULTADOS E COMENTÁRIOS}

A observação de diferentes tipos de ovos de $S$. mansoni, assim como do miracídio livre e de cascas, possibilitou uma tentativa de sistematização dos elementos esquistossomóticos encontrados em fezes humanas.

Cis estudos iniciais a respeito das variaçōes morfológicas dos ovos de Schistosoma foram feitos por Faust e Meleney (7) em 1924, utilizando o S. japonicum. Vogel (31), ainda utilizando esta mesma espécie, fêz uma classificação dos diferentes tipos de ovos encontrados em tecidos, principalmente de coêlhos e ratos. Rodrigues da Silva (28), empregando pela primeira vez o têrmo oograma no estudo das variações morfológicas do ôvo de $S$. mansoni, descreve os principais tipos de ovos evidenciados em material colhido por biópsia retal, método diagnóstico introduzido por ottolina e Atencio (18). Seguiram-se outros trabalhos, entre os quais os de Arantes Pereira \& col. (22), Viana Martins (15), $\mathrm{Pe}$ reira (23), todos utilizando o método de Ottolina e Atencio para a evidenciação do ôvo de $S$. mansoni. Prata (27), em seu estudo sôbre "Biópsia retal na esquistossomose mansoni", faz uma classificação pormenorizada dos diversos elementos esquistossomóticos. Outras observações sôbre os aspectos morfológicos dos $\mathrm{ovo}_{\mathrm{S}}$ de $S$. mansoni em tecido de animais de experimentação foram realizadas por Pellegrino \& cols. (21) e Loos (11).

A presente análise morfológica dos ovos de $S$. mansoni encontrados em fezes foi baseada principalmente na classificação de Prata (27) em biópsia retal, tendo sido entretanto, introduzidas algumas modificacôes.

Os ovos podem ser divididos inicialmente em ovos viáveis, ovos mortos e ovos inférteis.

\section{OVOS VIÃVEIS}

Os ovos maduros ( $160 \times 70$ micra), com o miracidio perfeitamente desenvolvido, apresentando características de vitalidade, como os movimentos de contração, as céIulas em chama oscilando e a movimentação ciliar (Fig. 1).
Miracidios livres $(230 \times 70$ micra) podem ser encontrados movimentando-se ativamente na preparação, tomando uma forma geralmente mais alongada, como já tem sido descrito. As cascas abandonadas pelo miracídio podem ser visualizadas apresentando uma fenda de sentido longitudinal ou transversal, com o miracídio muitas vêzes nas imediações (Fig. 2).

Os ovos imaturos viáveis foram visualisados sòmente nos $3 .^{\circ}$ e $4 .^{\circ}$ estágios do desenvolvimento. Os ovos do $3 .^{\circ}$ estágio ( 115 x 40 micra) apresentam-se com o embrião tomando $2 / 3$ da dimensão longitudinal do òvo, bem como grânulos finos e escuros localizados principalmente nos polos dos ovos (Fig. 3). O embrião apresenta-se na maioria das vêzes com uma tonalidade algo pardacenta, o que não é observado em material de biópsia retal, onde a massa embrionária do ôvo é mais clara. É possível que o sedimento fecal, mais escuro que a mucosa retal, promova esta diferença de tonalidade do embrião, ao exame microscópico. Outra possibilidade é a de tratar-se de um ôvo imaturo recentemente morto, que ainda mantenha tôdas as suas características estruturais.

Os ovos do $4 .^{\circ}$ estágio ( $150 \times 70$ micra) são um pouco maiores e o embrião toma todo o conteúdo do ôvo. Algumas vêzes já se nota um esbôço da estrutura do miracídio (Fig. 4). Entretanto, de acôrdo com Vianna Martins (15), é difícil afirmar-se a viabilidade ou não dos ovos imaturos, a não ser que se acompanhasse a evolução dos mesmos. Faust e Meleney (7) evidenciaram ovos imaturos viáveis de $S$. japonicum em fezes de cães experimentalmente infectados. Em fezes humanas, Faust (18) descreve a presenca dos ovos imaturos de $S$. japonicum.

Gliveira (17) refere, também, o encontro de ovos imaturos viáveis apenas de $3 .^{\circ}$ e $4 .^{\circ}$ estágios, em fezes de um paciente portador de esquistossomose mansoni.

Prata (27) acredita que, nas fezes, os ovos imaturos possam ser encontrados degenerados, apresentando glóbulos refringentes semelhantes à gotícula de gordura.

Lutz (12) narra o encontro de ovos imaturos em fezes, sem especificar sua viabiliclade ou não.

Ovos com distúrbio no desenvolvimento embrionário (138 x 68 micra). Foram vi- 
sualizados apenas 2 ovos com características de distúrbio no desenvolvimento embrionário, apresentando irregularidades no contôrno do miracídio, estrutura interna mal definida, mas com células em chama nìtidamente oscilantes (Fig. 5).

Ovos com miracidio añ̃o (152 x $75 \mathrm{mi}-$ cra). São ovos com a casca de dimensões semelhantes à dos ovos maduros viáveis, mas com um pequeno miracídio no interior, que apresenta entretanto, características de viabilidade, com cílios e células em chama que vibram (Fig. 6 e 7). Estes ovo. descritos por Loos (11) em roedores não são referidos por Prata (1957) em sua classificação.

Loos (11), critica o têrmo "miracídio retraído" usado por Pellegrino \& cols (21), pois acredita que não se trate de um miracídio desenvolvido que se contraiu, mas sim de um verdadeiro distúrbio no desen volvimento embrionário, dando origem a "Larvas anães". No entanto, quando Pellegrino \& cols. (21) descrevem os ovos com "miracídio retraído" referem-se a ovos ma-

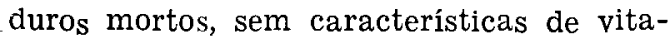
lidade, ao contrário do ôvo descrito por Loos (11), que apresenta um miracídio muito pequeno, mas com células em chama oscilantes. Êste mesmo tipo de ôvo viável foi observado por nós em quatro oportunidades. Eossivel ainda que se trate de um ôvo com o miracídio muito jovem e a casca dilatada por pressãn osmótica.

\section{OVOS MORTOS}

Ovos mortos maduros. Entre os ovos recentemente mortos, ainda segundo Prata (27), temos: Ovos com estrutura apagada (150 x 75 micra), em que o miracídio é perfeitamente delineado, mas já existem mo. dificações internas, tomando o miracídio um aspecto grumoso, sem movimentação de cílios e solenócitos (Figs. 8, 9 e 10). A seguir, os ovos tornam-se pardacentos, com granulações, perdendo-se muitas vêzes os limites do miracídio, que se confunde com a casca (Fig. 11). Êstes ovos são visualizados com certa freqüência em fezes, ao contrário do que tem sido descrito em biópsia retal. Êles apresentam dimensōes um pouco menores (140 × 60 micra) do que a dos ovos maduros viáveis, acreditando
Maldonado \& cols. (13) que possam diminuir de tamanho em decorrência da morte do miracídio. Os ovos mortos com miracidio retraido (160 × 70 micra) também pođem ser encontradus em fezes, apresentando-se como massa arredondada no centro do ôvo, às vêzes com cílios perfeitamente visiveis, mas sem apresentarem movimentação (Fig. 12).

Além dêsses tipos de ovos recentemente mortos descritos por Prata (27) em biópsia retal, foi-nos possivel ckservar em fezes ovos com miracidio degenerado, pardacento e às vêzes com granulações, mas, com a cosca nitidamente rompida (145 x 75 micra). E possível que, com o maior envelhecimento dos ovos, a casca torne-se mais frágil e rompa-se espontâneamente, ou então esta rutura possa ser ocasionada pelo movimento de homogeneização das fezes com bastão de vidro. Outra possibilidade, talvez menos freqüente, é o miracídio vivo não conseguir liberar. -se da casca após a ecdise, sobrevindo, a seguir, sua degeneração (Fig. 13) .

Ovos calcificados (140 × 70 micra), mortos há mais tempo, foram identificados

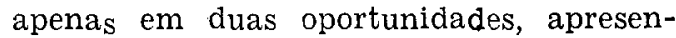
tando-se enegrecidos, mas com a espícula perfeitamente nítida (Fig. 14). Oliveira (17) também os observou em um paciente. A maioria dos autôres é de opinião que êste achado deva ser excepcional, sendo que Cunha (6) acredita que êste tipo de òvo não deva eliminar-se pelas fezes, sendo absorvido pelas reações tissulares de defesa do organismo.

Ovos mortos imaturos. São ovos de pequeno tamanho e que não se desenvolveram até a formação do miracidio. Em nosso material, os mais freqüentemente visualizados apresentavam características que não correspondem a nenhum dos ovos imaturos mortos descritos em biópsia retal. São ovos pequenos (118 x 41 micra), com a casca íntegra, e no interior uma estrutura pardacenta com formações aparentemente lacunares arrendondadas, principalmente em seus polos. Êstes às vêzes ficam afastados da casca, deixando um espaço vazio que permite uma fácil visualização da membrana vitelina (Fig. 15). Outras vêzes, as formações lacunares não são fàcilmente individualizadas (Fig. 16). 
Dentre os ovos imaturos mortos descritos por Prata (27) em biópsia retal, aquêles com características de embrião retraido não foram visualizados, pois, todos os que se apresentavam escurecidos, não o eram homogêneamence, além de apresentarem muitas vêzes a casca rompida, assemelhando-se mais a ovos hemitransparentes, sem contudo serem notadas nitidas zonas claras e escuras dispostas longitudinalmente.

Os ovos hemitronsparentes típ:cos (120 $\mathrm{x} 60 \mathrm{micra}$ ), foram, no entanto, evidenciados em algumas oportunidade:. Muitas vêzes, a área escura dêsses ovos era de tonalidade pardacenta, ao contrário do descrito em biópsia retal on de apresenta-se enegrecico (Fig. 17). Os ovos imaturos mortos granulosos (100 × 45 micra) foram observados em raras oportunidades, apresentando estruturas globulares esparsos, de tonalidade clara (Fig. 18).

\section{OVOS INFÉRTEIS}

Segundo Paraense (20), são ovos pequenos apresentando formas bizarra; e variadas, com ausência de embrião, uma vez que se trata de ovos não fecundados. Paraense (20) e Prata (27) descreveram êsses ovos no útero dos parasitos e no fígado de animais submetidos a infecções unisexuadas por fêmeas. Barreto (2) encontrou ovos inférteis em camundon $\equiv$ os infectados com cercárias, provenientes d 3 planorbídeos com infecção natural. Ovo: semelhantes aos acima descritos nunca puderam ser evidenciados nas fezes dos pa. cientes por nós estudados.

Outras alterações na forma do ôvo de $S$. mansoni parecem possíveis də serem ojservadas, como é o caso țo ôvo descrito por Bruijning (3) em fragmento de intistino de camundongo, após curio período do tratamentio antiparasitário. Lutz (12) refere ainda o encontro de um ôvo com duas

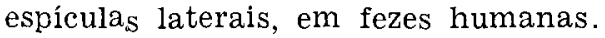

Esta análise dos ovos de $S$. monsoni em

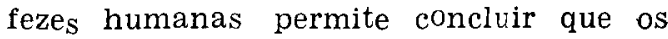
ovos observados são, com algumas alterações, semelhantes aos evidenciados em biópsia retal. Os ovos maduros viáveis são os mais freqüentes, aparecendo em uma percentagem de aproximadamente $67 \%$ dos elementos observados. Os ovos imatu- ros, tanto viáveis $(2,2 \%)$, como mortos (8\%), também podem ser visualizados. Entretanto, como já referiram Prata (27) e Oliveira (17), cêrca de $90 \%$ dos ovos eliminados pelas fezes, são viáveis ou recentemente mortos. Ovos calcificados mortos há mais tempo podem estar presentes nas fezes. Êste último achado, apesar de sua raridade, não deve ser desprezado no contrôle coproscópico dos pacientes submetidos à terapêutica antiparasitária, pois, a possibilidade dêste achado, se isolado, não deverá representar infecção esquistossomótica ativa.

Em nosso material, constituído de pacientes nunca submetidos à terapêtica anti-esquistossomótica, os ovos mortos foram sempre encontrados ao lado de ovos viáveis.

\section{II - ANÁLISE QUANTITATIVA}

\section{RESULTADOS}

Inicialmente, os 24 pacientes foram dividido, quanto à forma clínica da esquistossomose, em 2 grupos:

a) Forma hepatoesplênica: 11 cascs. ( 5 casos com menos de 20 anos de idade).

(6 casos com mais de 20 anos de idade) .

b) Forma hepatointestinal: 13 casos.

( 5 casos com menos de 20 anos de idade).

( 8 casos com mais de 20 anos de idade) .

No Quadro I, estão relacionadas as médias das contagens dos diver: $O_{S}$ tipos de ovo $_{S}$ de $S$. mansoni, encontrados por $\mathrm{cm} 3$ de fezes, em cada um dos dois grupos, assim como os percentuais destas médias.

Os mesmos 24 pacientes foram novamente reunidos, e a seguir dividido ${ }_{S}$ em 2 outros grupos, com relação ao grupo etário.

c) Pacientes com menos de 20 anos de idade: 10 casos.

( 5 casos portadores da forma hepatoesplênica) .

( 5 casos portadores da forma hepatointestinal). 


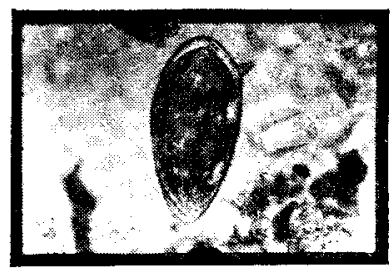

Fig. 1 - Ôvo maduro viável (X 125)

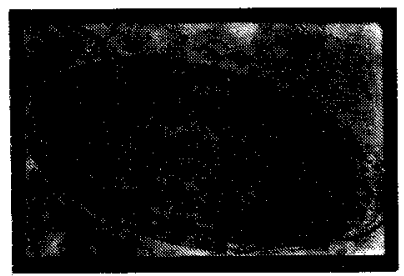

Fig. 4-Ôvo imaturo viável com a forma do miracídio já esboçada (X 250)

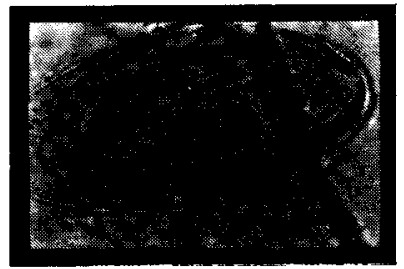

Fif. 7-Detalhe de outro ôvo com miracídis anão (X 250)

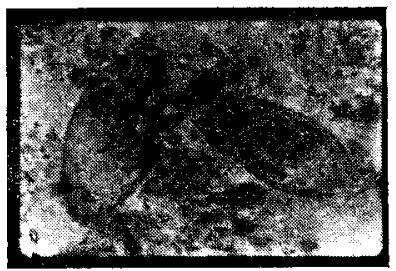

Fig. 2-Miracidio livre e a casca do ôvo (X 125)

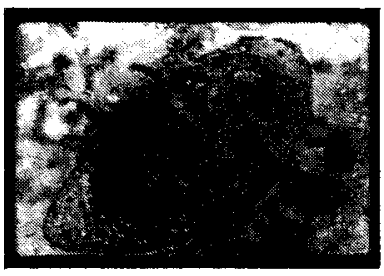

Fig. 5-Ôvo com distúy bio no desenvolvmento embrionário (X 250)

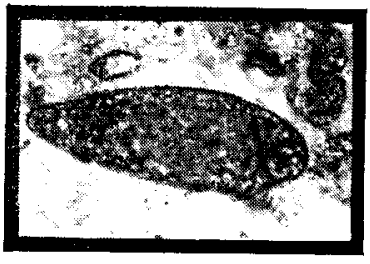

Fig. 3 - Ôvo imaturo viável do 3," estágio com o Embrião de tonalidade algo pardacenta (X 250)

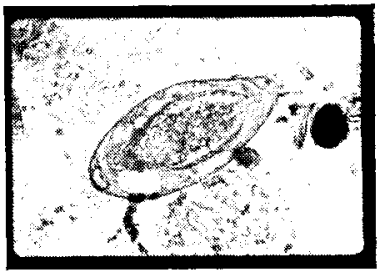

Fig. 6-Ôvo com mira cídio anão (X 125)

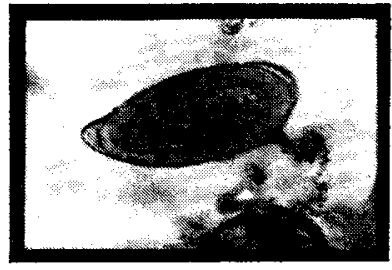

Fig. 8 - Ôvo maduro morto com estrutura apagadu (X 125)

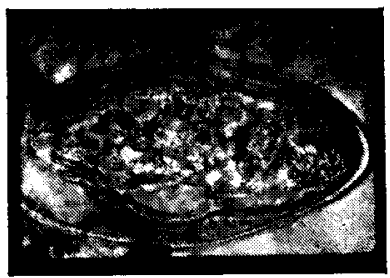

Fig. 9-Detalhes de um ôvo maduro morto, com estrutura apagada e formaçōes lacunares (X 250) 


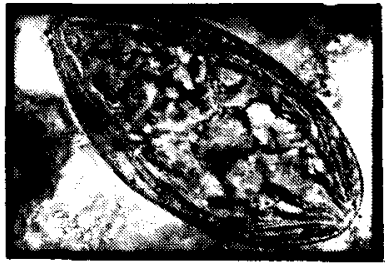

Fig. 10-Ôvo mañuro recentementre morio com o miracídio de aspecto grumoso (X 250)

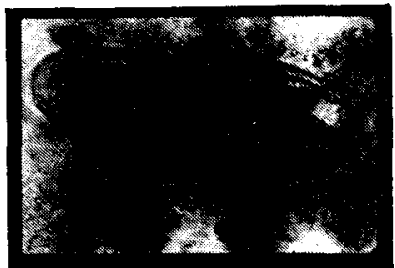

Fig. 13-Ôvo maduro morto, com a casa rom pida e o miracídio em degeneração ( $X$ 250)

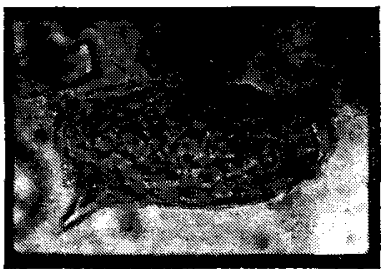

Fig. 16-ôvo imaturo morto, não se notands formações lacunares nos polos (X 250)

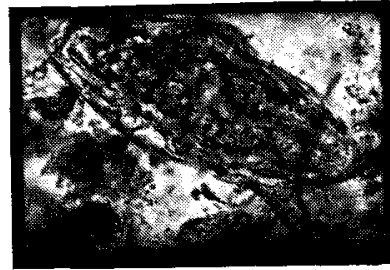

Fig. 11 -ôvo maduro morto, com o miracídio re traído (X 250)

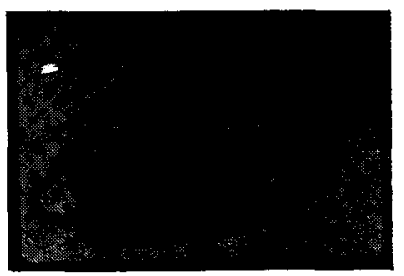

Fig. 14-Ôvo calcificado (X 250 .

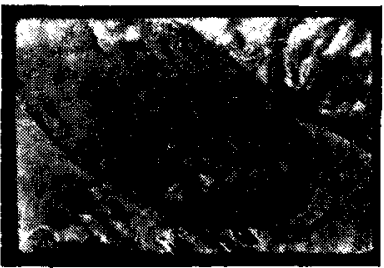

Fig. 12-Detalhe de um ôvo maduro morto, com : miracídio retraídio (X 250)

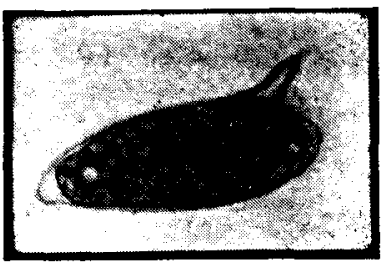

Fig, 15 - Ōvo i maturo morto, com formações la cunares arredondadas nos polos (X 250)

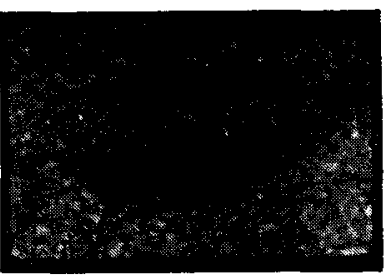

Fig. 17 - Ôvo imatu ro hemitransparenta (X 250)

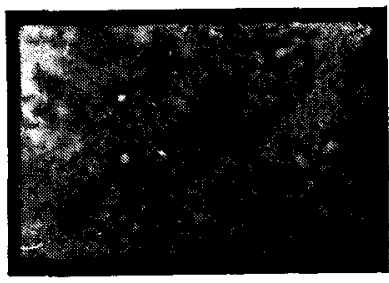

Fig. 18 - Ôvo i $m a t u r o$ morto granuloso, de as pecto fino e tonalidads clara (X 250) 
Q U A D R O I

OVOS DE S. MANSONI EM FEZES SEGUNDO A FORMA CLTICA

\begin{tabular}{|c|c|c|c|c|c|}
\hline & & \multicolumn{2}{|c|}{ 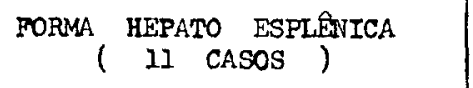 } & \multicolumn{2}{|c|}{$\begin{array}{l}\text { FORMA HEPATO INTESTINAL } \\
(13 \text { CASOS })\end{array}$} \\
\hline & & $\begin{array}{l}\text { Médiz de ovos } \\
\mathrm{P} / \mathrm{cm}^{3} \text { de fezes }\end{array}$ & Percentagern & $\begin{array}{l}\text { Médią de ovos } \\
\text { P/en de fezes }\end{array}$ & Percentagem \\
\hline & Maduros & 232 & 67,1 & 52,06 & 65.6 \\
\hline \multirow{3}{*}{ VIÁVEIS } & Imaturos & 6,44 & 1,8 & 2,81 & 3,5 \\
\hline & $\begin{array}{l}\text { Disturbio no } \\
\text { desenvolvimento }\end{array}$ & 0,23 & 0,1 & 0,12 & 0,1 \\
\hline & Miracialo anão & 1,95 & 0,5 & 0 & 0 \\
\hline \multirow{6}{*}{ MORTOS } & $\begin{array}{l}\text { Estrutura } \\
\text { apagada }\end{array}$ & 21,72 & 6,2 & 5,13 & 6,5 \\
\hline & $\begin{array}{l}\text { Granulosos } \\
\text { pardacentos }\end{array}$ & 31,4 & 9,5 & 10,0 & 12,6 \\
\hline & $\begin{array}{l}\text { Miractdio } \\
\text { retraído }\end{array}$ & 1,81 & 0,5 & 0,21 & 0,2 \\
\hline & $\begin{array}{l}\text { Casca rompida } \\
\text { com mirac1dio } \\
\text { em degeneração }\end{array}$ & 16,86 & 4,9 & 2,25 & 2,8 \\
\hline & Calcificados & 0,95 & 0,2 & 0 & 0 \\
\hline & Imaturos mortos & 32,26 & 9,2 & 6,87 & 8,7 \\
\hline \multicolumn{2}{|c|}{$\begin{array}{l}\text { SOMA DOS OVOS } \\
\text { VIAVEIS }\end{array}$} & 240,62 & 69,5 & 54,99 & 69,2 \\
\hline \multicolumn{2}{|c|}{$\begin{array}{l}\text { SOMA DOS OVOS } \\
\text { MORTOS }\end{array}$} & 105,0 & 30,5 & 24,46 & 30,8 \\
\hline TOTAL & DE OVOS & 345,62 & 100 & 79,45 & 100 \\
\hline
\end{tabular}

d) Pacientes com mais de 20 anos de idade: 14 casos.

( 6 casos portadores da forma hepatoesplênica).

(8 casos portadores da forma hepatointestinal).

No Quladro II, encontram-se as médias das contagens dos ovos de $S$. mansoni evi-

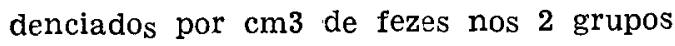
de pacientes, com mais e menos de 20 anos de idade.
Tanto no Quadro I como no Quadro II, as cascas rompidas sem o miracídio foram consideradas juntamente com os ovos maduros viáveis, pois ambos na prática têm a nesma significação. Nestess quadros os ovos imaturos mortos também foram considerados em conjunto, havendo grande predominância do tipo de ôvo imaturo morto descrito apenas em fezes (Fig. $15 \mathrm{e}$ 16), sôbre os ovos imaturos escuros, hemitransparentes e granulosos. 
Q UADRO II

OVOS DE S. MANSONI EM FEZES SEGUNDO O GRUPO ETARIO

\begin{tabular}{|c|c|c|c|c|c|}
\hline & & \multicolumn{2}{|c|}{$\begin{array}{l}\text { MENORES DE } 20 \text { ANOS } \\
\text { DE IDADE }(10 \text { CASOS })\end{array}$} & \multicolumn{2}{|c|}{$\begin{array}{l}\text { MAIORES DE } 20 \text { ANOS } \\
\text { DE IDADE }(14 \text { CASOS })\end{array}$} \\
\hline & & $\begin{array}{l}\text { Mediz de oyos } \\
\mathrm{P} / \mathrm{cm}^{2} \text { de fezes }\end{array}$ & Percentagem & $\begin{array}{l}\text { Médiz de ovos } \\
\mathrm{p} / \mathrm{cm}^{3} \text { de fezes }\end{array}$ & Percentagem \\
\hline & Maduros & 225 & 68,3 & 66,57 & 61,90 \\
\hline \multirow{3}{*}{ VIAVEIS } & Imaturos & 5,40 & 1,7 & 4,18 & 3,9 \\
\hline & $\begin{array}{l}\text { Disturbio no } \\
\text { desenvolvimento }\end{array}$ & 0,15 & 0,1 & 0,17 & 0,1 \\
\hline & Miracidio anão & 1,40 & 0,4 & 0,53 & 0,5 \\
\hline \multirow{6}{*}{ MORTOS } & $\begin{array}{l}\text { Estrutura } \\
\text { apagade }\end{array}$ & 23,50 & 7,2 & 7,24 & 6.7 \\
\hline & $\begin{array}{l}\text { Granulosos } \\
\text { pardacentos }\end{array}$ & 31,10 & 9,4 & 12,10 & 11,3 \\
\hline & $\begin{array}{l}\text { Miracidio } \\
\text { retra1do }\end{array}$ & 2,15 & 0,6 & 0,17 & 0,1 \\
\hline & $\begin{array}{l}\text { Casca rompida } \\
\text { com miracidio } \\
\text { em degenerą̧ão }\end{array}$ & 16,10 & 4,9 & 3,90 & 3,6 \\
\hline & Calcificados & 0,24 & 0,1 & 0.56 & 0.5 \\
\hline & Imaturos mortos & 24,20 & 7,3 & 12.31 & 11,4 \\
\hline \multicolumn{2}{|c|}{$\begin{array}{l}\text { SOMA DOS OVOS } \\
\text { VIAVEIS }\end{array}$} & 231,96 & 70,5 & 72,55 & 66,4 \\
\hline \multicolumn{2}{|c|}{$\begin{array}{l}\text { SOMA DOS OYOS } \\
\text { MORTOS }\end{array}$} & 97,39 & 29,5 & 36,18 & 33,6 \\
\hline \multicolumn{2}{|c|}{ TOTAL DE OVOS } & 329,35 & 100 & 107.73 & 100 \\
\hline
\end{tabular}

\section{COMENTÁRIOS}

Com relação à técnica de contagem de ovos, preferimos utilizar a de Barbosa (1), por ser um métoḑo simples e segundo Pereira Jr. \& cols. (24) estatisticamente mais precisa que outras comumente utilizadas. Entre as modificações sugeridas por Pereira Jr. \& cols. (24) à técnica original de Barbosa (1), não seguimos a que se refere à introdução de hidróxido de sóoiio, que tem por finalidade tornar o sedimen- to mais claro, facilitando a identificação dos ovos de helmintos. O hidróxido de sódio provoca a morte do miracídio do $S$. mansoni, o que em um exame de rotina de fezes não teria maior importância, mas em nossa análise cresce de valor, pela necessidade da separação entre os ovos maduros viáveis e ovos mortos.

As técnicas de contagem de ovos por volume de fezes não podem ser absolutamente precisas, pois existem causas de erros, como as variaçóes referiła $a_{S}$ por Scott (29) 
e por Maldonado (14) na postura de ovos pelas fêmeas, assim como a retenção de ovos pela gaze, no momento da filtragem. das fezes, como chamam a atenção Vianna Martins (15) e Klöetzel (10). No entanto, êstes métodos de contagem podem dar uma idéia aproximada do número de ovos eliminados.

Com relação às principais formas clíni cas da esquistossomose, verifica-se, pelo Quadro I, que a média do total do número de ovos eliminados, assim como de ovos viáveis e mortos, é nitidamente superior no grupo de pacientes portadores da forma hepatoesplênica, do que no grupo dos pacientes da forma hepatointestinal. No entanto, se em números absolutos as dife. reriças são nitidas, nos percentuais não existem grande variaçōes entre os diversos tipos de ovos eliminados, mantendo-se para os ovos viáveis em tôrno de $70 \%$ e para os ovos mortos em tôrno de $30 \%$.

Resultados semelhantes, demonstrando maior eliminação de ovos pelas fezes em pacientes portadores de formas graves da esquistossomose mansoni, foram encontrados por Klöetzel (10) e Barbosa (1), em áreas endêmicas da parasitose.

Cheever (4), usando técnica de perfusão de cadáveres para recuperação de $S$. mansoni, encontrou maior número de vermes nos portadores de fibrose de Symmers do que nos casos de infecção aparentemente assintomática. O número de ovos encontrados por grama de figado e por grama de fezes também foi maior no grupo que apresentava fibrose de symmers. Todos êstes dados sugerem ser maior o número de vermes nos individuos portadores de formas graves do que nos indivíduos portadores de formas leves da esquistossomose mansoni.

Trabalhos de Pessoa e Barros (25) e Pessoa \& cols. (26) chegam a esta mesma hipótese pelo estudo de outros aspectos da doença.

Acreditamos, assim, como a maioria dos autores, que, além do número de vermes, outros fatôres devem estar relacionados no desenvolvimento de formas graves da esquistossomose, entre os quais podem-se ressaltar os componentes imunoalérgicos.

A maior eliminação de ovos de $S$. mansoni pelas fezes de pacientes portadores da forma hepatoesplênica da esquistossomose, faz com que cresça o valor dos métodos coproscópicos de diagnóstico parasitológico nesta forma clínica da doença, como já assinalaram Meira (16), Prata (27) e Ferreira $\&$ cols. (9).

Com relação ao grupo etário dos 24 pacientes da presente casuística, pode-se verificar, pelo Quadro II, que a média do número de ovos tanto viáveis como mortos eliminados por cm3 de fezes é bem maior nos pacientes com menos de 20 aos de idadade do que no grupo de pacientes maiores de 20 anos de idade. Os percentuais relativos aos tipos de ovos eliminados permanecem, entretanto, mais ou menos semelhantes nos dois grupos etários, como já havia ocorrido com relação às duas principais formas clínicas da esquistossomose. Como já foi dito, todos os pacientes eram originários de zonas endêmicas da esquistossomose e, tendo em vista os dados colhidos pela anamnese, contraíram a parasitose na infância. Asim sendo, os pacientes menores de $\mathbf{2 0}$ anos de idade apresentavam provável infecção esquistossomótica mais recente e os maiores de 20 anos de idade, infecção mais antiga. Como foi observado, a eliminação de ovos foi menor nos indivíduos dêste último grupo etário, o que faz pensar em um decréscimo na eliminação de ovos a partir de certo tempo de infecção.

Scott (30) apresenta resultados sememelhantes e Klöetzel (10), baseado em observações em zona endêmica, conclui que "a contagem de ovos de $S$. mansoni nas fezes sofre acréscimo durante os primeiros anos de vida, atinge um máximo na adolescência, declinando bruscamente antes dos 20 anos de idade". Barbosa (1) refere que o máximo de eliminação de ovos em áreas endêmicas da parasitose, ocorre entre 14 e 19 anos de idade, decrescendo nos individuos mais velhos.

Nossos resultados parecem confirmar estas observações, embora tenham se baseado no estudo de pacientes originários de zonas endêmicas, mas delas afastados. Verificamos, ainda, que o número de ovos eliminados nas fezes, sendo menor a partir dos 20 anos de idade, não acarreta entretanto, grandes variações nos percentuais dos ovos viáveis e mortos eliminados.

Vogel \& Minning (32) acreditam que, a partir de certo tempo de infecção, deva haver uma inibição na postura dos ovos, e 
Klöetzel (10) é de opinião que processos imunitários devam ser prevalentes tanto em uma possivel destruição de parte dos vermes como também na inibição da pos- tura. No entanto, ao lado dessas hipóteses não deve ser afastada a possibilidade de uma diminuição na postura, relacionada com o envelhecimento dos parasitos.

\section{$S U M M A R Y$}

The main types of $\mathbf{S}$. mansoni eggs observed in faeces of patients coming from endemic ureas and never before submitted to treatment are described. The finding of mature and immature viable eggs, as weil as of several types of dead eggs, including the calcified (black eggs), is demonstrated. Attention is drawn to the rarity of the last mentioned type of eggs, which, however, must not be overseen in the coproscopic control after anti-schistosomal therapy.

The main dimensions of the eggs observed as well as their photomicrographs are presenied. A counting of $\mathbf{S}$. mansoni eggs per cm3 of faeces wos made. Higher counts of viable as well as dead eggs were found in the hepato-splenic form of the disease than in the hepato-intestinal form. However, it was observed that the percentage of the several types of eggs didn't differ very much in the two forms. It was supposed that besides other factors a higher number of worms in the host should play an important part in the development of the severe forms of schistosomiasis mansoni.

Subjects under 20 years had higher egg counts than those over 20. However, the percentage of the several types of eggs showed no great difference between the two age groups of patients. It was believed that besides the immunological factors the aging of the worm during the parasitaemia can be responsible for the decrease of the oviposition.

The data related to the global counting of $\mathrm{S}$. mansoni eggs in faeces of patient; of non endemic areas confirmed, in general, the results obtained by other uathors in $\mathbf{S}$. mansoni endemic areas, regarding the higher or lower egg counts in relation to the clinical form of the diseose or the age of patients.

\section{BIBLIOGRAFIA}

1 - BARBCSA, F.S. - Morbidade da Esquistossomose - Rev. Bras. Malariol. Doen. Trop., N. ${ }^{\circ}$ especial: 4, 1966.

2 - BARRETO, A.C. - Observações em tôrno da migração, acasalamento e postura de Schistosoma mansoni Tese. Bahia, 1961.

3 - BRUIJNING. C.F.A. - An Abnormal Schistosona mansoni egg Trop. Geogr. Med. 16: 164, 1964.

4 - CHEEver, A.W. - Perfusão de cadáveres para recuperação de Schistosoma mansoni - J. Bras. Med: Trop. 1: 39, 1967.

5 - COUTINHO, S.G., ANDRADE, C.M. \& FERREIRA, L.F. - A propósito dos aspectos morfológicos do ôvo de $S$. mansoni em fezes humanas Apresentado no III Cong. da Soc. Bras. Med. Trop. - Salvador, 1967.

6 - CUNHA, A.S. - Avaliação da terapêutica da esquistossomóse mansoni, pelo oograma -- Tese. Belo Horizonte, 1961 .

7 - FAUST, E.C. \& MELENEY, H.E. Studies on Schistosomiasis japonica - Am. J. Hyg. monographic series N.o 3: 1, 1924 .

8 - FAUST, E.C. - The diagnosis of Schistosomiasis japonica - II The diagnostic characteristics of eggs of the etiologic agent Schistosoma japonicum - Am. J. Trop. Med. 26: 113, 1946

9 - FERREIRA, L.F., COUTINHO, S.G., ARGENTO, C.A., ANDRADE, C.M., RUBENS, J., VALENTE, P. \& RODRIGUES DA SILVA, J. - O diagnóstico parasitológico na esquistossomose mansoni - Estudo comparativo entre o exame de fezes, biópsia retal e biópsia hepática - O Hospital, 69: 79, 1966.

10 - KLöETZEL, K. - Aspectos epidemiológicos da esquistossomose mansoni em urna população de Pernambuco. Suas correlações clínicas - Tese. São Paulo, 1962

11 - LOOS, B. - Über die Empfänglichkeit deutscher Kleinsäugetiere (Rodentia und Insectivora) für experimentelle Infektionen mit Schistosoma mansoni $\rightarrow \mathrm{Z}$. Tropenmed Parasit. 15: 56,1964 .

12 - LUTZ, A. - O Schistosomum mansoni e a schistosomatose segundo observaçōes feitas no Brasil - Mem. Inst. O.waldo Cruz, 11: 121, 1919.

13 - MALDONADO, J.F., ACOSTA, J. \& THILLET, C.J. - Biological studies on the miracidium of Schistosoma mansoni. Part II. Behavior of the unhatched miracidium in undiluted stools under divers environmental 
condtions - The Puerto Rico J. of Publ. Health and Trop. Med. 15: $153,1949$.

14 - MALDONADO, J.F. - (1965) citado por PESSOA, S.B. - Parasitlogia Médica, 7. ${ }^{\mathrm{a}}$ edição Editôra Guanabara Koogan. Rio de Janeiro, 1967.

15 - MARTINS, A.V. - Diagnóstico de laboratório da esquistossomose mansoni. Tese. Imprensa Cficial. Belo Horizonte, 1949.

16 - MEIRA, J.A. - Esquistossomose mansoni hepatoesplênica - Tese.. Fac. Med. São Paulo, 1951.

17 - OLIVEIRA, C.A. - Considerações sôbre o diagnóstico parasitológico na esquistossomose mansoni - J. Bras. Med. Trop. 1: 43, 1967.

18 - OTTOLINA, C. \& ATENCIO, H.M. - Nuevos camiños para el diagnostico clínico preciso de la schistosomiasis mansoni. Rev. Pol. Caracas. 12: 1,1943 .

19 - ÓTTOLINA, C. - El miracidio del Schistosoma mansoni - Rev. San. Assist. Social, 22: 1, 1957.

20 - PARAENSE, W.L. - Observações adicionais sôbre o sexo do Schistosoma mansoni nas infecções por cercárias de um único molusco - Mem. Inst. Oswaldo Cruz, 47: 535, 1949.

21 - PELlegrino, J., OLIVEIRA, C.A., FARIA, J. \& CUNHA, A.S. - New approach to the screening of drugs in experimental schistosomiasis mansoni in mice - The Am. J. Trop. Hyg. 11: 201, 1962 .

22 - PEREIRA, O.A., \& BARRETO NETO, M. - Biópsia retal múltipla e oograma na esquistossomose mansoni - Arq. Clin. 9: 127, 1949.

23 - PEREIRA, R.B - O métođo de OTTOLINA - ATENCIO no diagnósti- co da esquistossomose mansoni. Sua importância clínica. Belo Horizonte. Imprensa Oficial, 1950.

24 - PEREIRA, JR., D.B., GAMA, M.P. \& FERREIRA, L.F. - Os métodos quantitativos no exame parasitológico das fezes. A ser publicado.

25 - PESSOA, S.B., \& BARRGS, P.R. Notas sôbre a epidemiologia da esquistossomose mansoni no estado de Sergipe - Rev. Med. Cir. São Pau10, 13: 147, 1953 .

26 - PESSOA, S.B., SILVA, L.H.P. \& COSTA, L. - Observações sôbre a epidemiologia da esquistossomose no estado da Paraíba - Rev. Bras. Malar. \& Doen. Trop. 7: 305, 1955.

27 - PRATA, A. - Biópsia retal na esquistossomose mansoni. Bases e aplicações no diagnóstico e tratamento - Tese. Salvador, 1957.

28 - RODRIGUES DA SILVA, J. - Contribuição ao estudo das formas evolutivas da esquistossomose mansoni - Rev. Bras. Med. 1: 794, 1948.

29 - SCOTT, J.A. - The regularity of egg output of helmintic infestations, with especial reference to Schistosoma mansoni-Am. J. Hyg. 27: 155, 1938 .

30 - SCOTT, J.A. - La epidemiologia de Ia schistosomiasis en Venezuela Rev. San. Assist. Soc. 7: 771, 1942.

31 - VOGEL, H. - Úber Entwicklung, Lebenstauer und Tod der Eier von $B i$ lharzia japonica in Wirtsgewebe Dtsch. tropenmend. Ztsch. 46: 57, 1942 .

32 - VOGEL, H. \& MINNING, W. - Über die erworbene Resistenz von $\mathrm{Ma}$ cacus Rhesus gegenueber Schistosoma japonicum - $\mathrm{Z}$. Tropenmed. $\mathrm{Fa}$ rasit. 4: 418, 1953 . 


\section{NÔVO REGULAMENTO DO PREMIO GERHARD DOMACK}

Art. $1^{\circ}$ - $\mathrm{O}$ prêmio Gerhard Domagk é oferecido anualmente a partir de 1963, pela A CHIMICA "BAYER" S.A. em comemoração do centenário da fundação da FARBENFABRIKEN BAYER AG., de Leverkusen, Alemanha, ao autor ou autôres do melhor trabalho sôbre temas de medicina tropical (Doenças Infectuosas e Parasitárias, de Nutrição, Fisiologia e Higiene Tropicais), uma vez que o mesmo satisfaça às exigências dêste Regulamento.

Art. 2. ${ }^{\circ}$ - Concorrerão ao referido prêmio todos os trabalhos publicados na REVISTA DA SOCIEDADE BRASILEIRA DE MEDICINA TROPICAL, durante $o$ ano anterior.

Art. $3 .^{\circ}$ - O prêmio constará de uma importância em dinheiro, estipulada anualmente, e de uma medalha com o respectivo diploma assinado pelo Presidente e Secretário Geral da Sociedade. No caso de trabalho em colaboração, o prêmio em dinheiro será conferido à equipe, porém cada um dos co-autores receberá uma medalha e um diploma, que mencionará ser o prêmio pertencente à equipe.
Art. $4 .^{\circ}$ - Serão membros da Comissão Julgadora o Presidente da Sociedade Brasileira de Medicina Tropical, que a presidirá, e os integrantes do Conselho Consultivo da REVISTA DA SOCIEDADE BRASILEIRA DE MEDICINA TROPICAL.

Art. $5 .^{\circ}$ - Cada membro da Comissão julgadora indicará os $\mathbf{5}$ melhores trabalhos publicados durante o ano, sendo premiado aquêle que obtiver maior número de votos. Caberá ao Presidente da Sociedade Brasileira de Medicina Tropical a decisão final em caso de empate.

Art. $6^{0}$ - A Comissão julgadora deverá emitir seu parecer até a deta do início do Congresso anual da Sociedade Brasileira de Medicina Tropical, qliando o prêmio será entregue em sessão solene

Art. $7 .^{\circ}$ - Não caberá qualquer recurso ao parecer da Comissão Julgadora.

Art. $8 .^{\circ}$ - O Presidente da Sociedade Brasileira de Medicina Tropical será árbitro supremo para decidir as dúvidas surgidas na interpretação dêste Regulamento ou resolver qualquer dificuldade em sua execução. 